\title{
Nuclear Matrix Protein-22 and Telomerase Reverse Transcriptase Are Diagnostic Markers for Bladder Carcinoma in Egypt
}

\author{
Amel Abd Allah Hashim ${ }^{1}$, Mahmoud Youns ${ }^{12^{*}}$, Ahmed Abd Al-Rahman Soltan ${ }^{3}$, \\ Sahar Abd El-Mohsen Ali ${ }^{1}$ \\ ${ }^{1}$ Biochemistry and Molecular Biology Department, Faculty of Pharmacy, Helwan University, Cairo, Egypt; ${ }^{2}$ German Cancer Re- \\ search Center (DKFZ), Heidelberg, Germany; ${ }^{3}$ Clinical Oncology Department, Faculty of Medicine, Al-Azhar University, Cairo, \\ Egypt. \\ E-mail: ${ }^{*}$ mbio123@yahoo.com
}

Received July $5^{\text {th }}, 2011$; revised August $24^{\text {th }}, 2011$; accepted September $9^{\text {th }}, 2011$.

\begin{abstract}
Bladder carcinoma is the foremost oncologic problem among males in Egypt. Here, we evaluated the possible diagnostic value of the urinary Nuclear Matrix Protein-22 "NMP-22" and Telomerase Reverse Transcriptase " $h T E R T$ " among histological subtypes of bladder cancer. 120 males with non-muscle invasive bladder cancer, 21 non malignant bladder conditions and 21 healthy volunteers were included in this study. Estimation of hTERT and NMP-22 was done by PCR-ELISA and ELISA, respectively, from voided urine and results were compared to those of urine cytology. Results showed that urinary hTERT and NMP-22 were significantly higher in all cancer patients compared to control group. NMP-22 was able to discriminate between transitional cell bladder carcinoma "TCC" patients and squamous cell bladder carcinoma "SqCC" ones. Both markers succeded to discriminate between some transitional cell bladder carcinoma grades. Additionally, hTERT discriminated between some Tumor stages in both TCC and SqCC. Our results demonstrated that urinary hTERT and NMP-22 could be efficient urinary markers for the differential diagnosis of bladder cancer.
\end{abstract}

Keywords: Bladder Cancer, Urinary Markers, NMP-22, hTERT

\section{Introduction}

Despite advances in treatment and knowledge of pathogensis, bladder cancer remains significant cause of morbitity and mortality [1]. It is foremost oncologic problem among males in Egypt [2]. According to the Egyptian National Cancer Institute (NCI), it constitutes $30.3 \%$ of all cancers [3]. The frequency of schistsoma-related bladder carcinoma among Egyptians is about 31\% [4], where schistsomiasis is hyperendemic with overall prevalence of about $50 \%$.

Bladder cancer patients usually present themselves in an advanced stage of disease with symptoms of cystitis and relatively high recurrence rate [5]. Surgery is the most widely used treatment for bladder cancer. Beside the higher reported incidence of distant metastasis, local recurrence either alone or combined with systemic relapse has been shown to be experienced by $23 \%$ - $50 \%$ of locally advanced patients [6]. As for other cancers, blad- der cancer is most likely to be cured if early diagnosed and treated promptly. To date, ideal diagnostic tools and optimal predictors for bladder carcinoma are still not available.

Cystoscopy along with cytology is the mainstay for bladder cancer diagnosis. Cytology is specific but less sensitive particularly in low-grade disease. Cystoscopy on the other hand is invasive, relatively costy and also inconclusive particularly in case of cystitis, therefore, noninvasive markers for detecting bladder cancer are benificial. Urinary markers should be clinically useful, easy to perform, with minimum requirements for sample preparation, higher sensitivity and specificity [7].

Nuclear matrix protein "NMP-22" is a part of the internal structure framework of nucleus that defines its 3-D structure shape. It has an important role in DNA replication and transcription, RNA processing and regulation of gene expression $[8,9]$.

Telomerase is a specialized cellular ribonucleoprotein 
reverse transcriptase "hTERT" which stabilizes telomere length by adding hexameric (TTAGGG) repeats to the telomeric ends of chromosomes, thus compensating for the continued erosion of telomeres. Introduction of telomerase catalytic protein component into human cells maintains normal chromosome complement and normal manner of growth [10-12]. While all human tumors show higher telomerase activity, inhibition of telomerase may result in induction of apoptosis. Thus it may be a promising target for cancer therapy and/or diagnosis [13].

The present study was designed to evaluate the potential diagnostic value of urinary Nuclear Matrix Protein22 "NMP-22" and Telomerase Reverse Transcriptase "hTERT" among histological subtypes of bladder carcinoma using non-invasive diagnostic tools.

\section{Subjects and Methods}

\subsection{Subjects}

One hundred and sixty two male subjects were involved in our study, recruited from the clinical oncology department at Al-Azhar university hospitals. Patients were divided into two main groups: 120 with non-muscle invasive bladder cancer 72 with transitional cell bladder carcinoma "TCC" and 48 with Squamous cell bladder carcinoma "SqCC"), 21 patients with non malignant bladder conditions "NM". In addition to 21 age matched, healthy volunteers representing control group " $\mathrm{C}$ ".

Subjects included in our study were subjected to careful clinical examination, routine radiological investigations, urine cytology, and histopathological typing. All subjects provided informed written consents for participation, and the study was approved by the ethics committee of clinical oncology departement, Al-Azhar university hospitals.

\subsection{Methods}

A single voided urine sample was collected from all subjects in the early morning (second void of the day), for cytological examination and estimation of investigated markers. Samples handeling, storage and preparation were done according to manufacturers' instructions. hTERT activity was determined by TeloTAGGG Telomerase PCR-ELISA (Roche Diagnostics GmbH, Roche Applied Science, Mannheim, Germany) using Stratagene Mx 3000P Thermal Cycler (Agilent Technologies - Germany). NMP22 concentration was determined by enzyme linked imunosorbent assay (Matritech NMP-22 ${ }^{\circledR}$ Test $\mathrm{Ki}$, Bin ax Inc., Scarborough, USA) using semi automated StatFax 2100 Microplate reader (STAT FAX ${ }^{\circledR}$, USA).

\subsection{Statistics}

Statistics were done using GraphPad Instat tm (Graph software Inc., V 3.05, Ralf Stahlman, Purdue Univ.). Appropriate graphs were plotted using GraphPad Prism 5 (Graphpad software Inc., V 5.01, USA). Correlation coefficient was done using least square method. The accuracy indices were calculated according to Reed et al. [14]. The threshold value for optimal sensitivity and specificity was determined by receiver operating characteristics (ROC) analysis (SPSS Software package for Windows V 10.0, SPSS Inc., USA).

\section{Results}

Concerning age, and using Tukey-Kramer multiple tests, no significant variations were verified comparing each of non maignant bladder cancer, squamous cell bladder carcinoma and transitional cell bladder carcinoma to control group.

Our results showed that urinary levels of both hTERT and NMP-22 were significantly higher in both malignant and non malignant groups at $p<0.0001$. Both markers were significantly elevated in squamous cell bladder carcinoma and transitional cell bladder carcinoma groups when compared to control group (post-hoc test, p < 0.001 ), also in transitional cell bladder carcinoma group as compared to non malignant group ( $p<0.05,0.001$ respectively). Additionally, NMP-22 levels in squamous cell bladder carcinoma were significantly elevated compared to transitional cell bladder carcinoma and non malignant groups ( $p<0.05,0.001$ respectively). Clinical data of all subjects and urinary levels of hTERT and NMP-22 are shown in Tables $\mathbf{1}$ and $\mathbf{2}$ respectively.

Urinary levels of hTERT and NMP-22 were significantly higher in all squamous cell bladder carcinoma grades compared to $C$ group $\left(\mathrm{G}_{1}\right.$ and $\mathrm{G}_{3}$ at $\mathrm{p}<0.001$ and $\mathrm{G}_{2}$ at $\mathrm{p}<0.01$ ) with no discriminative ability between different grades. In transitional cell bladder carcinoma group, both markers were significantly elevated in all grades except grade $1\left(\mathrm{G}_{1}\right)$, when compared to control group $(\mathrm{p}<0.001)$. Both Grade $2\left(\mathrm{G}_{2}\right)$ and grade $3\left(\mathrm{G}_{3}\right)$ showed significant difference from that of $\mathrm{G}_{1}(\mathrm{p}<0.01)$.

Urinary levels of hTERT were significantly higher in tumor stages 2 and 3 of squamous cell bladder carcinoma group $(\mathrm{p}<0.001)$ and tumor stages 3 and 4 of transitional cell bladder carcinoma group $(\mathrm{p}<0.001)$ compared to control group. Tumor stage 4 varied significantly from that of T-stage $2(p<0.05)$ in squamous cell bladder carcinoma group, while in transitional cell bladder carcinoma group both of tumor stages 3 and 4 varied significantly from that of tumor stage $1(p<0.05)$.

Urinary levels of NMP-22 were significantly elevated in all tumor stages of both squamous cell bladder carcinoma (T-stages 2, 3 and 4 at $\mathrm{p}<0.001$, while T-stage 1 at $\mathrm{p}<0.01)$ and transitional cell bladder carcinoma groups (T-stages 1 and 2 at $\mathrm{p}<0.01$, while $\mathrm{T}$-stages 3 and 4 at $\mathrm{p}$ 
$<0.001)$ compared to control group with no discriminative ability among different T-stages.

As shown in Figure 1, urinary levels of hTERT (nm) showed statistically significant correlation with urinary levels of NMP-22 (U/ml) among all bladder cancer patients and transitional cell bladder carcinoma group $(\mathrm{p}<$ $0.0001)$, with no significant correlation between the two markers in squamous cell bladder carcinoma group.

Table 1. Urinary levels of hTERT in the study cohort.

\begin{tabular}{|c|c|c|c|c|c|}
\hline & & № & $\mathbf{M} \pm \mathbf{S E M}$ & Median & Range \\
\hline \multirow{3}{*}{ C } & All & & $0.14 \pm 0.04$ & 0.08 & $0.03-0.6$ \\
\hline & & 21 & & & \\
\hline & Age & & $52.1428 \pm 1.155$ & 52 & $45-60$ \\
\hline \multirow{3}{*}{ NM } & All & & $0.34 \pm 0.09$ & 0.2 & $0.02-1.4$ \\
\hline & & 21 & & & \\
\hline & Age & & $50.5714 \pm 1.371$ & 51 & $40-59$ \\
\hline \multirow{10}{*}{$\mathrm{SqCC}$} & All & & $0.79 \pm 0.11$ & $0.53^{* * *}$ & $0.03-2.8$ \\
\hline & & 48 & & & \\
\hline & Age & & $50.5416 \pm 0.6957$ & 50 & $42-59$ \\
\hline & $\mathrm{G}_{1}$ & 23 & $0.7417 \pm 0.1704$ & $0.55^{* * *}$ & $0.03-2.6$ \\
\hline & $\mathrm{G}_{2}$ & 18 & $0.87666 \pm 0.199$ & $0.525^{* * *}$ & $0.03-2.8$ \\
\hline & $\mathrm{G}_{3}$ & 7 & $0.73285 \pm 0.211$ & $0.63^{* * *}$ & $0.23-1.9$ \\
\hline & $\mathrm{T}-\mathrm{S}_{1}$ & 8 & $0.5775 \pm 0.201$ & 0.505 & $0.03-1.9$ \\
\hline & $\mathrm{T}-\mathrm{S}_{2}$ & 11 & $1.0636 \pm 0.2578$ & $0.63^{* * *}$ & $0.22-2.6$ \\
\hline & $\mathrm{T}-\mathrm{S}_{3}$ & 19 & $0.88368 \pm 0.1842$ & $0.55^{* * *}$ & $0.04-2.8$ \\
\hline & $\mathrm{T}-\mathrm{S}_{4}$ & 10 & $0.486 \pm 0.2456$ & $0.14^{\mathrm{b}}$ & $0.03-2$ \\
\hline \multirow{10}{*}{ TCC } & All & & $0.73 \pm 0.09$ & $0.56^{* * *, \#}$ & $0.03-3.28$ \\
\hline & & 72 & & & \\
\hline & Age & & $50.1944 \pm 0.6335$ & 49.5 & $41-60$ \\
\hline & $\mathrm{G}_{1}$ & 6 & $0.115 \pm 0.05948$ & 0.045 & $0.03-0.4$ \\
\hline & $\mathrm{G}_{2}$ & 36 & $0.775556 \pm 0.1205$ & $0.63^{* * *,} \S \S$ & $0.03-3.28$ \\
\hline & $\mathrm{G}_{3}$ & 30 & $0.793 \pm 0.1383$ & $0.555^{* * *}, \S \S$ & $0.08-3$ \\
\hline & $\mathrm{T}-\mathrm{S}_{1}$ & 22 & $0.46318 \pm 0.142$ & 0.3 & $0.03-3.28$ \\
\hline & $\mathrm{T}-\mathrm{S}_{2}$ & 14 & $0.4236 \pm 0.0663$ & 0.47 & $0.03-0.75$ \\
\hline & $\mathrm{T}-\mathrm{S}_{3}$ & 22 & $0.9914 \pm 0.1697$ & $0.715^{* * *, \varnothing}$ & $0.08-3$ \\
\hline & $\mathrm{T}-\mathrm{S}_{4}$ & 14 & $1.0336 \pm 0.2151$ & $0.81^{* * *, \varnothing}$ & $0.14-2.9$ \\
\hline
\end{tabular}

№: sample size, $\mathrm{M} \pm \mathrm{SEM}$ : mean \pm standard error, C: control, NM: non-malignant, TCC: transitional cell carcinoma, SqCC: squamous cell carcinoma, G: tumor grade, T-S: Tumor stage, hTERT: Telomerase Reverse Transcriptase. ${ }^{* * *} \mathrm{p}<0.001$ compared to $\mathrm{C}$ group, ${ }^{\#}<0.05$, compared to NM group, ${ }^{\S} \S_{\mathrm{p}}<0.01$ compared to $\mathrm{G}_{1}$ subgroup, ${ }^{\varnothing} \mathrm{p}<0.05$ compared to T-S subgroup, $^{\mathrm{b}} \mathrm{p}<0.05$ compared to T-S $\mathrm{S}_{2}$ subgroup using Kruskal-Wallis non-parametric ANOVA followed by Dunn's multiple comparison test. Cut-off value of hTERT $=0.2 \mathrm{~nm}$. Data were approximated to the second decimal. 
Table 2. Urinary levels of NMP-22 in the study cohort.

\begin{tabular}{|c|c|c|c|c|c|}
\hline & & № & $\mathbf{M} \pm \mathbf{S E M}$ & Median & Range \\
\hline \multirow{2}{*}{$\mathbf{C}$} & All & \multirow{2}{*}{21} & $0.29 \pm 0.07$ & 0.2 & $0-1.1$ \\
\hline & Age & & $52.1428 \pm 1.155$ & 52 & $45-60$ \\
\hline \multirow{2}{*}{ NM } & All & \multirow{2}{*}{21} & $28.36 \pm 15.53$ & 1.3 & $0-262$ \\
\hline & Age & & $50.5714 \pm 1.371$ & 51 & $40-59$ \\
\hline \multirow{9}{*}{$\mathrm{SqCC}$} & All & \multirow{2}{*}{48} & $115.38 \pm 11.85$ & $123^{* * *, \# \#, \text { a }}$ & $3.2-318$ \\
\hline & Age & & $50.5416 \pm 0.6957$ & 50 & $42-59$ \\
\hline & $\mathrm{G}_{1}$ & 23 & $111.9869 \pm 19.635$ & $117^{* * *}$ & $3.2-314$ \\
\hline & $\mathrm{G}_{2}$ & 18 & $116.5722 \pm 16.273$ & $128.5^{* * *}$ & $3.3-318$ \\
\hline & $\mathrm{G}_{3}$ & 7 & $123.4285 \pm 30.854$ & $119^{* * *}$ & $25-280$ \\
\hline & $\mathrm{T}-\mathrm{S}_{1}$ & 8 & $89.775 \pm 19.298$ & $111.5^{* *}$ & $3.2-150$ \\
\hline & $\mathrm{T}-\mathrm{S}_{2}$ & 11 & $129 \pm 28.584$ & $119^{* * *}$ & $16-318$ \\
\hline & $\mathrm{T}-\mathrm{S}_{3}$ & 19 & $125.7421 \pm 17.533$ & $126^{* * *}$ & $4.1-314$ \\
\hline & $\mathrm{T}-\mathrm{S}_{4}$ & 14 & $101.17 \pm 31.557$ & $125.5^{* * *}$ & $3.3-312$ \\
\hline \multirow{9}{*}{ TCC } & All & \multirow{2}{*}{72} & $90.22 \pm 13.70$ & $54.5^{* * *}, \# \#$ & $0-511$ \\
\hline & Age & & $50.1944 \pm 0.6335$ & 49.5 & $41-60$ \\
\hline & $\mathrm{G}_{1}$ & 6 & $4.8333 \pm 3.763$ & 0 & $0-23$ \\
\hline & $\mathrm{G}_{2}$ & 36 & $94.6667 \pm 19.625$ & $55.5^{* * *}, \S$ & $0-511$ \\
\hline & $\mathrm{G}_{3}$ & 30 & $101.9667 \pm 22.111$ & $73.5^{* * * *}, \S \S$ & $0-494$ \\
\hline & $\mathrm{T}-\mathrm{S}_{1}$ & 22 & $54.9090 \pm 17.086$ & $26^{* *}$ & $0-350$ \\
\hline & $\mathrm{T}-\mathrm{S}_{2}$ & 14 & $40.8571 \pm 7.925$ & $48.5^{* *}$ & $0-100$ \\
\hline & $\mathrm{T}-\mathrm{S}_{3}$ & 22 & $122.13636 \pm 28.587$ & $91.5^{* * *}$ & $4-494$ \\
\hline & $\mathrm{T}-\mathrm{S}_{4}$ & 14 & $144.9285 \pm 41.266$ & $75^{* * *}$ & $0-511$ \\
\hline
\end{tabular}

№: sample size, $\mathrm{M} \pm \mathrm{SEM}$ : mean \pm standard error, $\mathrm{C}$ : control group, NM: non-malignant group, TCC: transitional cell carcinoma group, SqCC: squamous cell carcinoma group, G: tumor grade, T-S: Tumor stage, NMP-22: Nuclear Matrix Protein-22. ${ }^{* * *} \mathrm{p}<0.001,{ }^{* *} \mathrm{p}<0.01$ compared to C group, ${ }^{\mathrm{a}} \mathrm{p}<0.05,{ }^{\# \#} \mathrm{p}<0.01$, $\#$ p $<0.001$ compared to TCC group, $\mathrm{p}<0.05$ compared to TCC group, ${ }^{\S \S} \mathrm{p}<0.01$ compared to $\mathrm{G}_{1}$ subgroup using Kruskal-Wallis non-parametric ANOVA followed by Dunn's multiple comparison test. Cut-off value of NMP-22 = $10 \mathrm{U} / \mathrm{ml}$. Data were approximated to the second decimal.

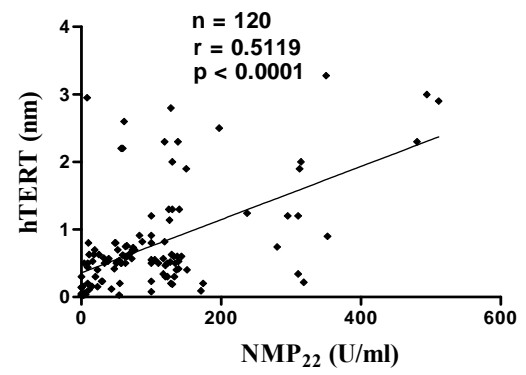

(a)

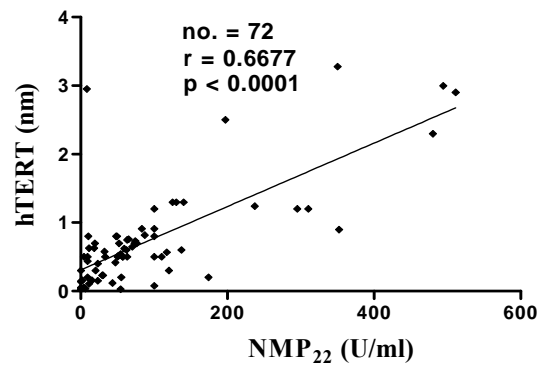

(b)

Figure 1. Correlations between urinary level of hTERT $(\mathrm{nm})$ and urinary level of $\mathrm{NMP}_{22}(\mathrm{U} / \mathrm{ml})$ in SqCC group (a) and TCC group (b). hTERT: Telomerase Reverse Transcriptase, $\mathrm{NMP}_{22}$ : Nuclear Matrix Protein-22. NMP $\mathbf{N}_{22}$ showed a statistically significant correlation with hTERT. Cut-off values: $h T E R T=0.2 \mathrm{~nm}$ and $\mathrm{NMP}_{22}=10 \mathrm{U} / \mathrm{ml}$. Spearman rank correlation coefficient (r), number of patients (no.). 
The diagnostic accuracy, sensitivity and specificity of hTERT and NMP-22 (at threshold $0.2 \mathrm{~nm}$ and $10 \mathrm{U} / \mathrm{ml}$ respectively) were $78.39 \%, 83.33 \%, 53.33 \%$ and $82.5 \%$, $78.57 \%, 85.71 \%$ respectively. Receiver operating characteristics (ROC) analysis for investigated parameters in bladder cancer patients is shown in Table 3, where quantitatively, area under the curve "AUC" is an overall measurement of accuracy. Combination of both markers improved sensitivity compared to each alone up to $89.19 \%$.

\section{Discussion}

Bladder carcinoma is the most prevalent cancer in Egypt and most of African countries [15]. Diagnosis is usually done at late tumor stages when therapy is rarely curative. The need for early detection must be emphasized [16].

We do believe that an ideal test for monitoring bladder cancer should be objective, noninvasive, easy to administer, interpret, and with high sensitivity and specificity. Many institutions routinely use screening cystoscopy, urine cytology and random bladder biopsy to find preclinical bladder cancer in elderly patients. Considerable efforts have been made to improve the ability of urologists to detect bladder cancer. Some tumor markers have been proposed for the detection of bladder tumors, but each test has its drawbacks and limitations. The present study assessed the accuracy of non-invasive tests for detection of bladder cancer.

In the present analysis, NMP-22 and hTERT were estimated in urine of patients with bladder cancer, in a trial to assess their value in early detection through a reliable non-invasive tool. Moreover, we investigated their role in differential diagnosis among different histological subtypes.

Both urinary hTERT and NMP-22 were significantly elevated in all bladder cancer patients. hTERT was able to discriminate between transitional cell bladder carcinoma and non malignant cancer. Additionally, NMP-22 was able to discriminate between transitional cell bladder carcinoma and squamous cell bladder carcinoma, also between both groups and non malignant cancer. Both markers showed elevated levels at all grades of transitional cell bladder carcinoma and squamous cell bladder carcinoma (except for $\mathrm{G}_{1}$ in transitional cell bladder car- cinoma group) with no discriminative ability between different grades in squamous cell bladder carcinoma group. Interestingly, both markers succeded to discriminate between advanced grades $\left(\mathrm{G}_{2}\right.$ and $\left.\mathrm{G}_{3}\right)$ from that of $\mathrm{G}_{1}$ in transitional cell bladder carcinoma patients. Although urinary NMP-22 was significantly elevated in all T-stages of both transitional cell bladder carcinoma and squamous cell bladder carcinoma subgroups with no discriminative ability, urinary hTERT succeded to discriminate between each pair of Tumor stages 3 and 1, 4 and 1 of transitional cell bladder carcinoma, 2 and 4 of squamous cell bladder carcinoma.

Our results are in complete agreement with Lahme et al. and Eissa et al. whom reported significantly higher levels of urinary NMP-22 in transitional cell bladder carcinoma than in benign bladder conditions and controls $[17,18]$. Additionally, data presented here are in line with Pattari and Dey whom introduced NMP-22 immunoassay as a cost-effective and sensitive screening test for detecting tumor in patients with urothelial carcinomas [19].

In accordance, recent study of Lekili et al. showed that urinary NMP-22 levels in bladder cancer patients were significantly higher than control [20]. Researchers attributed this elevation to release of nuclear mitotic apparatus protein from tumor cells in detectable levels, sometimes more than 25 -fold greater than normal cells, perhaps due to cell death $[21,22]$. In the contrary, there is data suggesting that intracellular NMP-22 levels correlate with degree of differentiation, tumor grade or tumor stage [20, 23].

Previous reports have pointed out that telomerase activity as well as the mRNA expression levels of its subunits is associated with malignancy in many bladder tumor histotypes [24-28], which is in line with our results on Egyptian bladder cancer patients. Additionally, and in agreement with our results, Mezzasoma et al. reported 11.4 fold increment of hTERT expression in washing fluids of bladder cancer patients compared to controls, reflecting the necessity in producing high levels of proteins required for its biological function [29]. Moreover, Li et al. showed that telomerase activity in urine was helpful in diagnosis of urothelial carcinomas and may be related to degree of differentiation [30]. Recent study by

Table 3. ROC curve analysis for bladder cancer patients.

\begin{tabular}{|c|c|c|c|c|}
\hline \multirow{2}{*}{ Variable } & \multirow{2}{*}{$\mathbf{A U C} \pm \mathbf{S E}$} & \multirow{2}{*}{ Asymptotic Significance } & \multicolumn{2}{|c|}{ Asymptotic 95\% CI } \\
\hline & & & Lower Bound & Upper Bound \\
\hline hTERT & $0.59 \pm 0.48$ & 0.070 & 0.496 & 0.685 \\
\hline NMP-22 & $0.767 \pm 0.38$ & 0.000 & 0.693 & 0.842 \\
\hline
\end{tabular}

hTERT: Telomerase Reverse Transcriptase, NMP-22: Nuclear Matrix Protein-22, SEM: Standard error. Cut-off value: NMP-22 = 10 U/ml, hTERT = 0.2 nm. 
Eissa et al. reported that hTERT showed significant difference between bladder cancer, benign bladder lesions, and healthy individuals $(p<0.001)$ [31]. Former studies reported that expression of hTERT and hTR mRNA, in voided urine samples, seems to correlate positively with tumor stage and grade [24,29,32]. Here we reported that urinary levels of hTERT positively correlated with that of NMP-22 in both bladder cancer group and transitional cell bladder carcinoma group, but not in squamous cell bladder carcinoma, in line with Abd El Gawad et al. [33].

Cytologic examination of urinary sediment has become a standard procedure for diagnosis and monitoring of patients with bladder tumors. Sensitivity of voided urinary cytology is $40 \%-80 \%$ and specificity is $85 \%$ $100 \%$ in various studies [34].

In our study, accuracy, sensitivity and specificity of hTERT and NMP-22 were $78.39 \%, 83.33 \%, 53.33 \%$ and $82.5 \%, 78.57 \%, 85.71 \%$ respectively, demonstrating better sensitivity of NMP-22 than urine cytology. In previous studies, sensitivity and specificity of hTERT were $62 \%-85 \%$ and $91.3 \%-100 \%$ [19], $70 \%-86 \%$ and $60 \%$ - $90 \%$ respectively [7]. Researchers showed that the overall sensitivity of NMP-22 was $70 \%$ at reference value of $10 \mathrm{IU} / \mathrm{ml}$ [35], while others demonstrated that sensitivity and specificity of NMP-22 were $68.5 \%-88.5 \%$ and $65.2 \%-91.3 \%$ [7], $92.9 \%$ and $70.6 \%$ respectively as compared with voided urine cytology (sensitivity of $76.2 \%$ and specificity of $76.5 \%$ ) [36]. In line with our results, Poulakis et al. reported that NMP-22 tests are better than voided urine cytology for detecting superficial and low-grade bladder cancer but they have significantly lower specificity [37].

Our results demonstrate that analyses of urinary hTERT and NMP-22 expression are noninvasive, reproducible and objective tests that may have the potential to replace voided urine cytology and used as diagnostic markers for Bladder carcinoma in Egypt.

\section{Conclusions}

To our knowledge, this is the first study demonstrating the clinical significance of NMP-22 and hTERT among different histological subtypes of bladder cancer using non-invasive procedures.

\section{Acknowledgements}

We gratefully thank the staff of the Clinical Oncology Departement at Al-Azhar University Hospitals for their great efforts and support.

\section{REFERENCES}

[1] C. T. Nguyen and J. S. Jones, "Defining the Role Of NMP-22 In Bladder Cancer Surveillance," World Journal of Urology, Vol. 26, No. 1, 2008, pp. 51-58. doi:10.1007/s00345-007-0226-Z

[2] Statistical Report For NCI of Egypt, 2004. http://www.nci. edu.eg/

[3] N. G. El-Mawla, M. N. El-Bolkainy and H. M. Khaled, "Bladder Cancer in Africa: Update," Seminars in Oncology, Vol. 28, No. 2, 2001, pp. 174-178.

doi:10.1053/sonc.2001.21961

[4] M. Muscheck, H. Abol-Enein, K. Chew, D. Moore , V. Bhargava, M. A. Ghoneim, P. R. Carroll and F. M. Waldman, "Comparison of Genetic Changes in SchistosomeRelated Bladder Transitional and Squamous Bladder Cancers Using Comparative Genomic Hybridization," Carcinogenesis, Vol. 21, No. 9, 2000, pp. 1721-1726. doi:10.1093/carcin/21.9.1721

[5] W. Zhao, X. S. Wang, H. T. Niu, L. L. Wang, B. M. Han and S. J. Xia, "Clinical Relevance of Heparanase Mrna Expression in Bladder Cancer and Its Usefulness as a Detection Marker in Voided Urine," Molecular Medicine, Vol. 2, No. 2, 2009, pp. 327-331.

[6] M. S. Zaghloul, "Adjuvant and Neoadjuvant Radiotherapy for Bladder Cancer: Revisited," Future Oncology, Vol. 6, No.7, 2010, pp. 1177-1191. doi:10.2217/fon.10.82

[7] P. Dey, "Urinary Markers of Bladder Carcinoma," Clinica Chimica Acta, Vol. 340, No. 1-2, 2004, pp. 57-65. doi:10.1016/j.ccen.2003.11.008

[8] R. Berezney, "The Nuclear Matrix: A Heuristic Model for Investigating Genomic Organization and Function in the Cell Nucleus," Journal of Cellular Biochemistry, Vol. 47, No. 2, 1991, pp. 110-123. doi:10.1002/jcb.240470204

[9] R. H. Getzenberg, B. R. Konety, T. A. Oeler, M. M. Quigley, A. Hakam, M. J. Becich and R. R. Bahnson, "Bladder Cancer Associated Nuclear Matrix Proteins," Cancer Research, Vol. 56, No. 7, 1996, pp. 1690-1694.

[10] N. W. Kim, M. A. Piatyszek, K. R. Prowse, C. B. Harley, M. D. West, P. L. Ho, G. M. Coviello, W. E. Wright, S. L. Weinrich and J. W. Shay, "Specific Association of Human Telomerase Activity with Immortal Cells and Cancer," Science, Vol. 266, No. 5193, 1994, pp. 2011-2015. doi:10.1126/science.7605428

[11] E. H. Blackburn, "Telomeres and Telomerase: Their Mechanisms of Action and Effects of Altering Their Functions," FEBS Letters, Vol. 579, No. 4, 2005, pp. 859-862. doi:10.1016/i.febslet.2004.11.036

[12] C. J. Cairney and W. N. Keth, "Telomerase Redefined: Integrated Regulation of Htr and Htert for Telomere Maintenance and Telomerase Activity," Biochimie, Vol. 90, No. 1, 2008, pp. 13-23. doi:10.1016/j.biochi.2007.07.025

[13] M. L. Quek, K. Sanderson, S. Daneshmand and J. P. Stein, "New Molecular Markers for Bladder Cancer Detection," Current Opinion in Urology, Vol. 14, No. 5, 2004, pp. 259-264. doi:10.1097/00042307-200409000-00003

[14] R. Reed, D. Holmes, J. Weyers and A. Jones, "Choosing and Using Statistical Tests," Practical Skills in Biomolecular Sciences, 2nd Edition, Pearson Education, 
2003, p. 485.

[15] N. G. El-Mawla, M. N. El-Bolkainy and H. M. Khaled, "Bladder Cancer in Africa: Update," Seminars in Oncology, Vol. 28, No. 2, 2001, pp. 174-178. doi:10.1053/sonc.2001.21961

[16] H. M. Khaled, I. Abdel-Salam, M. Abdel-Gawad, A. Metwally, S. El-Demerdash, M. El-Didi, A. Morsi and L. Ishak, "Evaluation of The BTA Tests for the Detection of Bilharzial Related Bladder Cancer: The Cairo Experience," European Urology, Vol. 39, No. 1, 2001, pp. 9194. doi:10.1159/000052418

[17] S. Lahme, K. H. Bichler, G. Feil and S. Krause, "Comparison of Cytology and Nuclear Matrix Protein 22 for the Detection and Follow-Up of Bladder Cancer," Urologia Internationalis, Vol. 66, No. 2, 2001, pp. $72-77$. doi:10.1159/000056574

[18] S. Eissa, M. Swellam, M. Sadek, S. Mourad, O. Ahmady and A. Khalifa, "Comparative Evaluation of the Nuclear Matrix Protein, Fibronectin, Urinary Bladder Cancer Antigen and Voided Urinary Cytology in the Detection of Bladder Tumors," Journal of Urology, Vol. 168, No. 2, 2002, pp. 465-469. doi:10.1016/S0022-5347(05)64659-9

[19] S. K. Pattari and P. Dey, "Urine: Beyond Cytology for Detection of Malignancy," Diagnostic Cytopathology, Vol. 27, No. 3, 2002, pp. 139-142. doi:10.1002/dc.10135

[20] M. Lekili, E. Sener, M. A. Demir, G. Temeltas, T. Muezzinoglu and C. Buyuksu, "Comparison of the Nuclear Matrix Protein 22 with Voided Urine Cytology in the Diagnosis of Transitional Cell Carcinoma of the Bladder," Urological Research, Vol. 32, No. 2, 2004, pp. 124-128. doi:10.1007/s00240-003-0394-2

[21] V. B. Lokeshwar and M. S. Soloway, "Current Bladder Tumor Tests: Does Their Projected Utility Fulfill Clinical Necessity?" Journal of Urology, Vol. 165, No. 4, 2001, pp. 1067-1077. doi:10.1016/S0022-5347(05)66428-2

[22] K. H. Lee, "Evaluation of the NMP-22 Test and Comparison with Voided Urine Cytology in the Detection of Bladder Cancer," Yonsei Medical Journal, Vol. 42, No. 1, 2001, pp. 14-18.

[23] A. Di Carlo, D. Terracciano, A. Mariano, A. Oliva, M. D'Armiento and V. Macchia, "Role of Cytokeratins, Nuclear Matrix Proteins, Lewis Antigen and Epidermal Growth Factor Receptor in Human Bladder Tumors," International Journal of Oncology, Vol. 23, No. 3, 2003, pp. 757-762.

[24] M. Muller, "Telomerase. It's Clinical Relevance in the Diagnosis of Bladder Cancer," Oncogene, Vol. 21, No. 4, 2002, pp. 650-655. doi:10.1038/sj.onc. 1205071

[25] M. A. Sanchini, R. Gunelli, O. Nanni, S. Bravaccini, C. Fabbri, A. Sermasi, E. Bercovich, A. Ravaioli, D. Amadori and D. Calistri, "Relevance of Urine Telomerase in Diagnosis of Bladder Cancer," Journal of the American Medical Association, Vol. 294, No. 16, 2005, pp. 20522056. doi:10.1001/jama.294.16.2052

[26] Y. Takihana, T. Tsuchida, M. Fukasawa, I. Araki, N. Tanabe and M. Takeda, "Real-Time Quantitative Analy- sis for Human Telomerase Reverse Transcriptase Mrna And Human Telomerase RNA Component Mrna Expressions as Markers for Clinicopathologic Parameters in Urinary Bladder Cancer," International Journal of Urology, Vol. 13, No. 4, 2006, pp. 401-408.

[27] S. Bravaccini, M. A. Sanchini, A. M. Granato, R. Gunelli, O. Nanni, D. Amadori, D. Calistri and R. Silvestrini, "Urine Telomerase Activity for the Detection of Bladder Cancer in Females," Journal of Urology, Vol. 178, No. 1, 2007, pp. 57-61. doi:10.1016/i.juro.2007.03.025

[28] A. Bennett, "Telomerase and Other Novel Approaches to Bladder Cancer Detection," Clinical and Laboratory Science, Vol. 21, No. 3, 2008, pp. 185-190.

[29] L. Mezzasoma, C. Antognelli, C. Del Buono, F. Stracci, E. Cottini, G. Cochetti, V. N. Talesa and E. Mearini, "Expression and Biological-Clinical Significance of hTR, hTERT and CKS2 in Washing Fluids of Patients with Bladder Cancer," BMC Urology, Vol. 10, 2010, p. 17. doi:10.1186/1471-2490-10-17

[30] Z. Li, C. Kong, P. Wang, X. Liu and T. Liu, "Telomerase Activity in Urine in Diagnosis and Recurrence Surveillance of Urothelial Carcinoma," Chinese Medical Journal, Vol. 115, No. 11, 2002, pp. 1650-1652.

[31] S. Eissa, M. Swellam, A. Amin, M. E. Balbaa, G. A. Yacout and T. M. El-Zayat, "The Clinical Relevance of Urine-Based Markers for Diagnosis of Bladder Cancer," Medical Oncology, Vol. 28, No. 2, 2011, pp. 513-518. doi:10.1007/s12032-010-9422-6

[32] S. Weikert, H. Krause, I. Wolff, F. Christoph, M. Schrader, T. Emrich, K. Miller and M. Muller, "Quantitative Evaluation of Telomerase Subunits in Urine as Biomarkers for Non Invasive Detection of Bladder Cancer," International Journal of Cancer, Vol. 117, No. 2, 2005, pp. 274-280. doi:10.1002/ijc.21168

[33] I. A. Abd El Gawad, H. S. Moussa, M. I. Nasr, E. H. El Gemae, A. M. Masooud, I. K. Ibrahim and N. M. El Hifnawy, "Comparative Study of NMP-22, Telomerase, And BTA in the Detection of Bladder Cancer," Journal of the Egyptian National Cancer Institute, Vol. 17, No. 3, 2005, pp. 193-202.

[34] U. Kumar, P. Dey, A. K. Mondal, S. K. Singh and H. Vohra, "DNA Flow Cytometry and Bladder Irrigation Cytology in Detection of Bladder Carcinoma," Diagnostic Cytopathology, Vol. 24, No. 3, 2001, pp. 153-156. doi:10.1002/1097-0339(200103)24:3<153::AID-DC1032 $>3.0$.CO;2-P

[35] M. S. Soloway, J. V. Briggman and G. A. Carpinito, "Use of a New Tumor Marker, Urinary NMP-22, in the Detection of Occult or Rapidly Recurring Transitional Cell Carcinoma of the Urinary Tract Following Surgical Treatment," Journal of Urology, Vol. 156, No. 2, 1996, pp. 363-367. doi:10.1016/S0022-5347(01)65851-8

[36] R. Srivastava, V. K. Arora, S. Aggarwal, A. Bhatia, N. Singh and V. Agrawal, "Cytokeratin-20 Immunocytochemistry in Voided Urine Cytology and Its Comparison With Nuclear Matrix Protein-22 and Urine Cytology in the Detection of Urothelial Carcinoma," Diagnostic Cyto- 
pathology, 6 January 2011, In Press.

[37] V. Poulakis, U. Witzsch, R. De Vries, H. M. Altmannsberger, M. J. Manyak and E. Becht, "A Comparison Of Urinary Nuclear Matrix Protein-22 and Bladder Tumor Antigen Tests with Voided Urinary Cytology in Detecting
And Following Bladder Cancer: The Prognostic Value of False-Positive Results," British Journal of Urology International, Vol. 88, No. 7, 2001, pp. 692-701.

doi:10.1046/j.1464-410X.2001.02355.X 